\title{
PENGARUH METODE LATIHAN SISTEM SET TERHADAP PENINGKATAN KEMAMPUAN DAYA LEDAK OTOT LENGAN PADA ATLET BOLABASKET FIK UNP
}

\author{
Nirwandi $^{1}$, Yaslindo ${ }^{2}$, Kamal Firdaus ${ }^{3}$ \\ Program Studi Pendidikan Kepelatihan Olahraga Universitas Negeri Padang. Jalan Prof.Dr.Hamka Air \\ Tawar Barat, Padang, 25132, Indonesia.
}

\begin{abstract}
Abstrak
Penelitian ini bertujuan untuk melihat pengaruh sistem set terhadap peningkatan daya ledak otot lengan pada atlet FIK UNP Padang. Jenis penelitian ini adalah penelitian exsperimen semu yang dilakukan di GOR PPSP Pembangunan UNP. Sampel penelitian ini adalah pemain bolabasket putra FIK UNP yang berjumlah 10 orang yang diberikan perlakuan 16 kali latihan. Teknik pengambilan data menggunakan two hand medicine ball push. Data yang telah terkumpul digunakan untuk menguji hipotesis yang menggunakan uji t. Sebelum uji t dilakukan terlebih dahulu dilakukan uji persyaratan analisis yaitu uji normalitas dan uji homogenitas. Hasil dari uji hipotesis yang menggunakan statistik uji $\mathrm{t}$ dapat disimpulkan sebagai berikut : Sistem set tidak berpengaruh secara signifikan terhadap peningkatan kemampuan daya ledak otot lengan dapat diperoleh nilai $\mathrm{t}_{\text {hit }} 1.74<\mathrm{t}_{\mathrm{tab}} 2.26$ dan $\mathrm{p} 0.11>0.05 \alpha$
\end{abstract}

Kata Kunci : Sistem set, kemampuan daya ledak otot lengan pada atlet bolabasket FIK UNP

\begin{abstract}
This study aims to look at the effect of system set on increasing arm muscle explosive power in UNP Padang FIK athletes. This type of research is a quasi-experimental research conducted at the PPSP GOR of UNP Development. The sample of this research was 10 male basketball players from FIK UNP who were treated 16 times. Data collection techniques using two hand medicine ball push. The collected data is used to test hypotheses using the $t$ test. Before the $t$ test is carried out, the analysis requirements test is carried out, namely the normality test and homogeneity test. The results of hypothesis testing using t test statistics can be summarized as follows: The set system does not significantly influence the increase in arm muscle explosive ability, the value of thit is $1.74<\mathrm{t}_{\mathrm{tab}} 2.26$ and $\mathrm{p} 0.11>0.05 \alpha$
\end{abstract}

Keywords: System set, arm muscle explosive ability in basketball FIK UNP athletes

\section{Pendahuluan}

Konsep bermain bolabasket menurut Tomoliyus (2001:11) adalah: menghasilkan skor (nilai) dengan memasukkan bola ke keranjang (basket) dan mencegah tim lain melakukan hal serupa. Permainan bolabasket merupakan olahraga yang memiliki aktivitas gerak yang menuntut berbagai keterampilan, teknik dan taktik disamping kondisi yang prima bagi pelakunya. Disamping itu permainan bolabasket menuntut kreativitas teknik, keberanian untuk berbuat sesuatu dan kepercayaan akan kemampuan sendiri dan kerjasama tim yang baik.
Selanjutnya menurut Kusyanto (1999:227) : "Bola harus dipompa kencang agar mampu melambung sampai $120-140 \mathrm{~cm}$ dan mempunyai papan pantul dan kayu keras setebal $3 \mathrm{~cm}$, panjang $180 \mathrm{~cm}$ dan lebar $120 \mathrm{~cm}$, tinggi papan $275 \mathrm{~cm}$, ditempelkan di belakang ring untuk memantulkan bola jika tidak masuk ke dalam keranjang, jaraknya $15 \mathrm{~cm}$ di belakang ring, dilengkapi dengan keranjang yang terdiri dari ring dan jala. Ring dan besi keras dengan garis tengah $45 \mathrm{~cm}$, jala terdiri dari tali putih yang digantung pada ring, panjang jala $40 \mathrm{~cm}$ ".

Menurut PB. PERBASI (2008), permainan bolabasket adalah suatu permainan yang dimainkan oleh dua regu putera atau puteri

Pengaruh metode latihan sistem set .......107 
yang masing-masing regu terdiri dari lima orang pemain dengan menggunakan lapangan permainan berbentuk persegi panjang dengan ukuran $28 \mathrm{~cm} \mathrm{x} 15 \mathrm{~cm}$ dan bola yang terbuat dari karet yang berlapis sejenis kulit dengan keliling 75-78 cm, dengan berat 600 - 650 gram.

Seperti yang dikemukakan oleh Frank S.

Pyke dalam PENGDA PERBASI (2005:12) bahwa: "Basketball is a game of habbit, artinya permainan bolabasket adalah olahraga yang berdasarkan kebiasaan".

Dari uraian di atas dimaksudkan bahwa permainan bolabasket adalah olahraga yang berdasarkan kebiasaan, artinya untuk menjadi seorang pemain bolabasket yang baik sangat dibutuhkan proses latihan atau bermain secara berulang-ulang atau berkelanjutan (continue) agar memperoleh teknik, taktik dan kondisi prima dalam permainan yang bagus. Kemudian menurut Bompa dalam Syahara (2005:56) mengemukakan bahwa : untuk menjadi seorang atlet dicabang olahraga bolabasket dapat dimulai dari usia dini yaitu 7-8 tahun. Dalam olahraga permainan bolabasket, usia latihan spesialisasi dimulai pada umur 12-19 tahun, sedangkan usia pencapaian puncak prestasi usia 20-25 tahun, atlet bolabasket lebih matang dalam mengatur strategi dan teknik permainan.

Jon dalam Wawan

(2007:38) mengemukakan bahwa :

Dalam passing (mengumpan) dapat dilakukan beberapa macam teknik yaitu : chest pass (umpan dada), bounce pass (umpan pantul), two-handed overhead (umpan atas kepala menggunakan dua tangan), baseball (umpan bisbol/lemparan samping), shuffle pass (umpan sambil berlari), dribble pass (umpan dribble), wrap-around (umpan selubung) dan behind the back (umpan di belakang punggung).

Masing-masing passing memiliki kegunaan khusus dalam situasi pertandingan yang berbeda-beda. Dalam penelitian ini akan dilakukan pada kemampuan passing dada (chest pass). Menurut Ambler (1982:25): "mengoperkan bola dari posisi setinggi dada merupakan teknik yang paling sering dipakai dalam permainan biasa". Teknik mengoperkan bola setinggi dada ini disebut demikian karena memang bola dilempar dari daerah di depan dada pemain.

Menurut Witarsyah

mengatakan bahwa : passing adalah keahlian mendasar yang sangat penting dipelajari oleh setiap pemain bolabasket. Passing merupakan salah satu kunci keberhasilan serangan sebuah tim dan sebuah unsur penentu tembakantembakan yang berpeluang besar mencetak angka. Ketepatan passing yang hebat tidak boleh diremehkan. Ini bisa memotivasi rekan-rekan tim, menghibur penonton dan menghasilkan permainan yang tidak individualis.

Masing-masing passing memiliki kegunaan khusus dalam situasi pertandingan yang berbeda-beda. Dalam penelitian ini akan dilakukan pada kemampuan passing dada (chest pass). Menurut Ambler (1982:25): "mengoperkan bola dari posisi setinggi dada merupakan teknik yang paling sering dipakai dalam permainan biasa". Teknik mengoperkan bola setinggi dada ini disebut demikian karena memang bola dilempar dari daerah di depan dada pemain.

Passing dada (chest pass) dapat dilakukan sesuai dengan kondisi permainan sebenarnya, disini dipertimbangkan passing dada (chest pass) dengan cepat dan tepat serta sukar dirampas oleh lawan. Menurut Witarsyah (2005:5) mengatakan bahwa : gerakan passing dada (chest pass) adalah operan yang paling umum dalam permainan bolabasket, karena dapat dilakukan dengan cepat dan tepat dari setiap posisi. Passing dada (chest pass) yang tepat adalah salah satu kunci keberhasilan serangan sebuah tim dan semua unsur penentu tembakan-tembakan yang berpeluang besar mencetak angka. Ketepatan passing dada (chest pass) yang hebat tidak boleh diremehkan. Ini bisa memotivasi rekan-rekan tim, menghibur penonton dan menghasilkan permainan yang tidak individualis. Seorang pengumpan yang terampil mampu melihat seluruh lapangan, mengantisipasi perkembangan dalam pertandingan yang penuh serangan dan memberikan umpan pada saat yang tepat.

Apabila pelaksanaan passing dada (chest pass) berjalan dengan lancar sehingga terciptanya kerjasama tim yang baik dan dapat mengendalikan tempo permainan sehingga mudah untuk menciptakan peluang demi peluang untuk 
melakukan shooting dan akhirnya poin demi poin terkumpul, maka terciptalah suatu kemenangan. Oleh sebab itu passing dada (chest pass) merupakan salah satu teknik dasar penentu kemenangan di dalam cabang olahraga bolabasket).

Berdasarkan kutipan-kutipan di atas, dapat dikemukakan bahwa kemampuan passing dada (chest pass) merupakan salah satu kemampuan teknik dasar passing dalam permainan bolabasket yang penting peranannya untuk mengatur tempo permainan, mengadakan serangan balik, melewati lawan serta membuat kesempatan untuk melakukan tembakan dan dapat menjaga bola tetap berada di pihak sendiri.

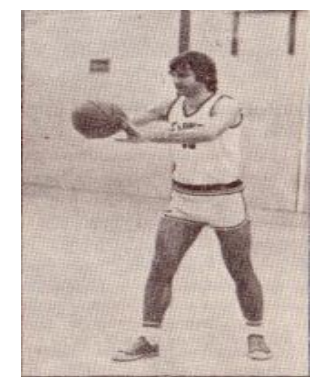

Gambar 1: Bentuk Pelaksanaan Chest pass (Ambler, 1982:24-29)

\section{Hakekat kemampuan daya ledak otot lengan}

Daya ledak merupakan salah satu dari komponen biomotorik yang penting dalam kegiatan olahraga, karena daya ledak akan menentukan seberapa jauh melempar bola dan sebagainya.

Menurut Bompa dalam Syahara (2004: 20-23) daya ledak (power) merupakan hasil dari dua kemampuan yaitu kekuatan dan kecepatan dan dipertimbangkan sebagai suatu kemampuan untuk menampilkan kekuatan yang maksimum dalam waktu yang paling pendek.

Daya ledak otot lengan merupakan kemampuan dasar kondisi fisik yang merupakan tumpuan utama dalam pencapaian prestasi bolabasket, khususnya dalam melakukan passing dada (chest pass). Perolehan poin (angka) tidak akan dapat tercipta apabila passing dada (chest pass) yang dilakukan tidak sampai atau berjalan dengan lancar kepada pemain yang berada pada posisi bebas untuk melakukan shooting ke ring basket. Passing dada (chest pass) merupakan salah satu teknik dasar dalam menyusun strategi penyerangan.

Selanjutnya Nossek dalam Asril (1999:74) menyatakan bahwa faktor yang mempengaruhi daya ledak adalah kekuatan dan kecepatan kontraksi. Sedangkan menurut Herre dalam Asril (1999:74) menyatakan bahwa faktor yang mempengaruhi kekuatan otot sebagai daya ledak adalah jenis serabut otot, luas otot rangka, jumlah cross bridge, sistem metabolisme energi, sudut sendi dan aspek psikologis.

Berdasarkan kutipan-kutipan di atas, dapat disimpulkan bahwa daya ledak otot lengan merupakan kemampuan otot lengan untuk menampilkan kekuatan maksimum dan kecepatan maksimum secara eksplosive dalam waktu cepat dan singkat untuk mencapai tujuan yang dikehendaki sehingga otot lengan yang menampilkan gerakan eksplosive ini sangat kuat dan cepat dalam berkontraksi serta dipengaruhi oleh faktor-faktor tertentu seperti sistem metabolisme energi dan lain sebagainya.

a. Otot-otot yang terlibat dalam gerakan chest pass

Adapun otot-otot lengan yang sangat berperan sekali dalam melakukan (chest pass) menurut Basoeki (1988:28) adalah:

1) Flexor digitorum

2) Palmaris longus

3) Flexor carpiradialis

4) Brachioradialis

5) Pronator teres

6) Brachialis

7) Tricep brochii, medial head

8) Biseps brachii

9) Flexor corpi ulnaris

10) Extensor carpi ulnaris

11) Anconeus

12) Triceps brochii, lateral head

13) Triceps brochii, long head

14) Coracobrachialis

15) Teres minor

16) Infraspinatus

17) Teres major

18) Latissimus dorsi

19) Subscapularis

20) Serratus anterior

Untuk lebih jelasnya gambar otot-otot lengan dapat dilihat pada gambar di bawah ini : 


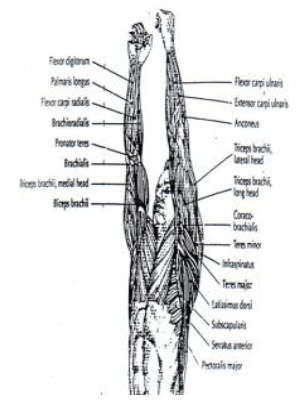

Gambar 2: Otot-otot lengan yang dominan digunakan dalam pelaksanaan passing (Delavier, 2001:63)

\section{b. Sistem Energi}

Nawawi (2008:1) menyatakan bahwa energi adalah kapasitas untuk melakukan kerja (work of capacity). Kerja merupakan hasil perkalian antara tenaga (force) dengan jarak (distance). Semakin berat suatu pekerjaan maka semakin banyak kebutuhan energi.

$$
\text { Selanjutnya, Syahara }
$$
menyatakan bahwa seluruh energi yang dipakai dalam dunia biologis pada dasarnya bersumber dari matahari. Sumber energi yang dapat dengan segera digunakan untuk setiap aktivitas manusia seperti pada sistem biologis datang dari pemecahan senyawa kimia tunggal $\rightarrow$ ATP (Adenosine Triphospate). Metabolisme produksi ATP otot dan sel berasal dari pembebasan energi melalui pemecahan zat makanan dan senyawa lain yang melibatkan serangkaian reaksi kimia anaerobik maupun aerobik (karbohidrat, selulosa, protein dan lemak). Untuk otot yang bekerja, maka sistem energinya tergantung dari intensitas dan jangka waktu yang digunakan dalam kegiatan yang dilakukan.

Menurut Nawawi (2008: 2), ATP dipecah menjadi ADP (Adenosine Diphosphate) dan PI (Phosphate Inorganik). Putusnya ikatan phosphate berenergi tinggi tersebut menghasilkan energi sebesar 8-12 kcal. Energi inilah yang akan digunakan untuk kerja semua sel jaringan tubuh termasuk sel otot rangka. Oleh karena itu ATP ini terdapat di dalam semua sel jaringan tubuh, sebab ATP yang tersedia pada satu sel tidak bisa dipakai untuk sel yang lain, melainkan untuk kebutuhan dari sel itu sendiri.
Berdasarkan kutipan-kutipan di atas sumber energi yang paling utama akan mempengaruhi proses yang lain adalah energi yang berasal dari matahari. Energi kimia dapat diubah menjadi energi mekanik yang akan menghasilkan gerak. Untuk melakukan berbagai aktivitas tubuh memerlukan gerak, gerak dihasilkan dari kontraksi dan relaksasi otot rangka, untuk bisa bekerja otot rangka memerlukan energi, energi diambil dari pemecahan bahan kimia di dalam otot yaitu ATP (Adenosine Triphosphate).

Selanjutnya Nawawi

(2008:4-5) menyatakan bahwa :

Sistem energi dalam aktivitas fisik terdiri dari dua bagian yaitu sistim anaerobik dan sistim aerobik. Sistim anaerobik adalah proses metabolisme energi tanpa menggunakan oksigen, sedangkan sistim aerobik adalah proses metabolisme energi dengan menggunakan oksigen. Kedua sistim energi ini terdapat di dalam semua cabang olahraga, hanya predominant system nya yang berbeda-beda tergantung dari intensits, waktu, jarak dan frekuensi dari aktivitas tersebut. Pada cabang olahraga yang intensitasnya tinggi, maka sistim energinya lebih dominan anaerobik, sebaliknya cabang olahraga dengan intensitas yang rendah, maka sistim energinya lebih dominan aerobik.

c. Ciri-ciri latihan (power) daya ledak Harsono (1993:13-14) mengatakan:

1) Melawan beban berat badan sendiri atau tambahan beban luarrelatif ringan.

2) Gerakan latihan dinamis dan cepat.

3) Gerakan merupakan gerakan yang utuh, singkat dan harmonis.

4) Bentuk bahan latihan cyclic atau acyclic.

5) Intensitas sub maksimal atau maksimal.

d. Prinsip - prinsip yang harus diperhatikan dalam latihan daya ledak menurut Harsono (1993:14), Prinsip-prinsip dalam latihan daya ledak adalah:

1) Volume beban latihan dalam 1 sesi latihan $4-6$ set.

2) Intensitas submaksimal atau maksimal, beban yang diangkat (berat barbell) 1/4 - $1 / 3$ berat badan atlet.

3) Ulangan angkatan per - set 12-15 kali. 
4) Recovery antar set $2-3$ menit.

\section{Hakekat Metode Latihan}

Latihan adalah aktivitas atau kegiatan yang terdiri dari berbagai bentuk sikap dan gerak, terarah, berulang-ulang, dengan beban yang kian bertambah guna memperbaiki efisiensi kemampuan. Menurut Bompa (1994:2) "latihan merupakan proses pengulangan yang sistematis, progresif dengan tujuan akhir memperbaiki prestasi olahraga. Kunci utama dalam memperbaiki prestasi olahraga adalah sistem latihan yang diorganisasikan secara baik. Program latihan harus mengikuti konsep periodesasi, disusun dan direncanakan secara baik berdasar cabang olahraga, agar sistem energi atlet mampu beradaptasi terhadap kekhususan cabang olahraga".

Efektifitas bentuk-bentuk latihan untuk mengoptimalkan prestasi motorik olahraga yang komplek (kemampuan kondisi) ditentukan oleh perbandingan komponen-komponen beban serta aturan-aturannya. Komponen beban tersebut adalah:

a. Intensitas beban menunjukan kuatnya beban selama pelaksanaan suatu latihan dalam satuan waktu. Intensitas beban dapat ditentukan secara persentase (kuantitatif) untuk prestasi maksimal individu dalam setiap latihan. Beban berhubungan dengan massa atau jumlah berat yang digunakan dalam membangun kekuatan. Beban super maksimal atau suatu beban memiliki kekuatan maksimum dalam banyak kasus beban berkisar antara 100-175\% dapat digunakan dengan mengaplikasikan eksentrik, atau melawan metode gaya berat dikenal juga sebagai negatif. Beban-beban supermaksimal digunakan selama pengembangan kekuatan maksimum hanya oleh atlet-atlet dengan latar belakang yang kuat dalam latihan kekuatan. Sebagian atlet yang lain hanya terbatas pada beban hingga $100 \%$. Beban maksimal berkenaan dengan beban $90-100 \%$ satuan maksimum. Beban tinggi digunakan ketika bekerja dengan beban $60-90 \%$ dari satuan maksimum. Beban sedang berkenaan dengan persentase antara 30-60\% dari satuan maksimum. Beban rendah ialah dibawah 30\% dari satuan kapasitas. Pada setiap bentuk latihan, intensitas beban ditentukan oleh : kecepatan dalam meter/detik, frekwensi gerakan, besar beban yang diangkat (digerakkan), tinggi dan jauh lompatan, dan pada cabang olahraga permainan ditentukan oleh tempo permainan itu sendiri.

b. Volume beban menunjukkan jumlah isi atau materi latihan (kuantitas). Jumlah pengulangan, jumlah jarak yang ditempuh dan jumlah beban yang digerakan, juga waktu latihan yang efektif. Jika beban lebih tinggi maka jumlah repetisi dan irama penampilan berkurang, pada pengembangan kekuatan maksimum (90$175 \%)$ jumlah repetisi hanya sedikit (1-3), dilakukan secara perlahan-lahan. Pada latihan yang ditujukan untuk mengembangkan power $(30-80 \%$ dan maksimum) jumlah repetisi sedang (5-10) dan penampilan mereka dinamis. Seperti pada daya tahan otot, jumlah repetisi tinggi, kadang-kadang sampai pada suatu batas (250 atau lebih) penampilannya lambat, irama sedang. Untuk daya tahan otot asiklis jumlah repetisi antara 10-30, sedangakan pada siklis mendekati batas.

c. Interval beban menggambarkan perbandingan waktu dari pembebanan ke pemulihan dalam satu satuan latihan. Interval beban dengan lama beban mempengaruhi intensitas beban.

d. Lama beban latihan menunjukkan jumlah waktu suatu latihan, satu seri latihan atau jumlah waktu untuk menyelesaikan suatu jarak tertentu. Lama beban bersama dengan interval beban dapat mempengaruhi intensitas beban.

Berdasarkan penjelasan di atas dapat disimpulkan bahwa latihan sangat penting untuk peningkatan kemampuan individu dalam meningkatkan prestasi. Latihan juga dipengaruhi oleh beberapa komponen untuk pencapaian tujuan latihan yang efektif dan maksimal.

Adapun pemberian latihan yang dilakukan yaitu selama 16 kali. Sesuai dengan pendapat Tom Rosandic dalam Maidarman (1986:22) yang terjemahannya sebagai berikut :

Latihan yang giat dan frekuensi yang banyak dengan waktu yang pendek akan 
menghasilkan kemajuan yang besar. Ini adalah kemungkinan lebih baik latihan dalam 3 kali seminggu dengan waktu yang pendek. Sedangkan latihan seminggu sekali dengan waktu yang panjang tidak menghasikan kemajuan".

\section{Metode Latihan Sistim Set}

Menurut Harsono (1988:196) metode latihan sistim set adalah latihan yang menggunakan beberapa repetisi suatu bentuk latihan kemudian disusul dengan suatu masa istirahat, selanjutnya melakukan lagi repetisi semula (gerakan yang sama), ada yang melakukan 2 set untuk suatu bentuk latihan ada pula yang melakukan 3 set. Kemudian Ambeim dalam Afdal (1991:3) menjelaskan bahwa program latihan 3 set setiap kerjanya menghasilkan peningkatan kekuatan yang terbesar dari pada memakai program latihan 1 atau 2 set. Dalam pelaksanaan latihan sistim set ini, dijelaskan oleh Fall dkk dalam Afdal (1991:1) bahwa jumlah pengulangan dalam satu set tidak lebih dari 12 dan tidak kurang dari 6 kali pengulangan.

Metode latihan sistim set juga terdapat istirahat, Sajoto dalam Yendrizal (1997:27) menjelaskan sistim set ini perlu memberikan kesempatan kepada otot untuk beristirahat, maka antara set satu ke set berikutnya harus ada waktu istirahat antara 1-2 menit.

Menurut para ahli lainnya, Harold dan kawan-kawan dalam Afdal (1991:10) "it appears that for maximum strength gain no more than 12 or less than 6 repetition". Artinya jumlah pengulangan dalam satu set tidak kurang dari 6 dan tidak lebih dari 12 pengulangan.

Sistim set banyak dipakai dalam metode latihan pembentukan dan peningkatan kondisi fisik atlet. Latihan kondisi sangat mendukung terhadap latihan teknik seperti yang dijelaskan oleh Harsono (1988:100) bahwa tanpa kondisi fisik yang baik, seorang atlet tidak akan dapat mengikuti latihan, karena kondisi fisik sangat menunjang bahkan sangat menentukan keberadaannya dalam olahraga. Hal ini dipertegas Syafruddin (1993:139) bahwa kemampuan kondisi fisik sangat menentukan bagi seorang atlet untuk mengoptimalkan teknik-teknik yang dipelajarinya. Kondisi fisik yang baik merupakan syarat dalam meningkatkan dan mengembangkan kemampuan teknik.

Jadi dari pengertian-pengertian di atas dapat disimpulkan bahwa metode latihan sistim set adalah sistem latihan yang lebih menitikberatkan pada pengulangan atau repetisi dalam latihannya. Jumlah repetisi yang ditentukan diharapkan minimal 6 kali, sedangkan set minimal 3 kali dengan lama istirahat antara pos ke pos hanya 30 detik, sedangkan istirahat untuk satu set tidak terlalu lama sekitar 2 menit (istirahat aktif) sesuai dengan beban latihan, karena semakin berat beban yang diberikan semakin lama masa istirahat.

Kemampuan chest pass merupakan kemampuan passing dari jarak dekat yang dilakukan secara kuat dan cepat. Untuk dapat melakukan chest pass tersebut seorang atlet harus memiliki kondisi fisik yang baik dan menunjang kepada kemampun chest pass khususnya daya ledak otot lengan.

\section{Metode Penelitian}

Jenis yang digunakan dalam penelitian ini adalah penelitian eksperimen semu. Penelitian ini dilaksanakan di GOR PPSP Pembangunan UNP. Populasi penelitian ini adalah atlet-atlet tim B putera bolabasket Fakultas Ilmu Keolahragaan UNP yang berusia 19-24 tahun yang berjumlah 10 orang. Instrumen dilakukan dengan melakukan tes terhadap pemain bolabasket yang dijadikan sampel. Tes dilakukan dengan cara mengukur kemampuan daya ledak otot lengan yaitu dengan tes "two hand medicine ball-push" (Nurhasan, 1984 : 57), dengan koefisien realibilitas tes sebesar 0,81 dan validitas 0,77 serta objektivitas 0,99 .

Pendeskripsian data dan pengujian hipotesis dalam penelitian ini diolah dengan memakai statistik deskriptif dan inferensial dengan rumus uji $\mathrm{t}$ sampel terikat. Sebelum dilakukan analisis uji t, terlebih dahulu dilakukan uji persyaratan analisis, yaitu normalitas data dan homogenitas, dan uji $\mathrm{t}$ hanya dapat digunakan untuk menguji perbedaan mean dari dua tes yang diambil dari populasi yang normal dan kelompok yang homogen (Isparjadi:1998). 
Setelah uji normalitas dilakukan, maka dilakukan analisis uji t, dengan rumus sebagai berikut :

$$
\mathrm{t}=\frac{\left|\overline{\mathrm{X}_{1}}-\overline{\mathrm{X}_{2}}\right|}{\sqrt{\frac{\sum \mathrm{D}^{2}-\frac{\left(\sum D\right)^{2}}{N}}{N(N-1)}}}
$$

Keterangan :

$\mathrm{t}=$ Harga uji t yang dicari

$\overline{\mathrm{X}}_{1}=$ Mean tes awal

$\overline{\mathrm{X}}_{2}=$ Mean tes akhir

$\mathrm{D}=$ Beda antara skor tes awal dan akhir

$\mathrm{N}$ = Pasangan

Df $\quad=$ Derajat kebebasan $(\mathrm{df})=\mathrm{N}-1$

$\sum \mathrm{D}=$ Jumlah semua beda

$\sum \mathrm{D}^{2}=$ Jumlah semua beda yang dikuadratkan (Isparjadi, 1998:57)

\section{Hasil Penelitian dan Diskusi}

Data dalam penelitian ini merupakan data primer yaitu daya ledak otot lengan yang diukur dengan menggunakan bola medisin (medicine ball).

\section{Tabel 3. Deskripsi Data Daya Ledak Otot Lengan Sistem Set}

\begin{tabular}{|c|c|c|c|}
\hline \multirow[b]{2}{*}{$\begin{array}{l}\mathbf{N} \\
\mathbf{O} .\end{array}$} & \multirow[b]{2}{*}{ NAMA } & \multicolumn{2}{|c|}{ SISTIM SET } \\
\hline & & $\begin{array}{l}\text { PRE- } \\
\text { TEST }\end{array}$ & $\begin{array}{c}\text { POST- } \\
\text { TEST }\end{array}$ \\
\hline 1. & RONI & $5.5 \mathrm{mtr}$ & $6 \mathrm{mtr}$ \\
\hline 2. & IHSAN & $5 \mathrm{mtr}$ & $4.5 \mathrm{mtr}$ \\
\hline 3. & SUSANTO & $4.8 \mathrm{mtr}$ & $5.4 \mathrm{mtr}$ \\
\hline 4. & RANDY & $4.5 \mathrm{mtr}$ & $4.5 \mathrm{mtr}$ \\
\hline 5. & BONIEK & $4.5 \mathrm{mtr}$ & $4.5 \mathrm{mtr}$ \\
\hline 6. & RAHMAN & $4.2 \mathrm{mtr}$ & $5 \mathrm{mtr}$ \\
\hline 7. & ARIEF & $4.2 \mathrm{mtr}$ & $4.5 \mathrm{mtr}$ \\
\hline 8. & REZKY & $4 \mathrm{mtr}$ & $4.4 \mathrm{mtr}$ \\
\hline 9. & DEDI & $4 \mathrm{mtr}$ & $4 \mathrm{mtr}$ \\
\hline 10. & VEBI & $3.2 \mathrm{mtr}$ & $3.2 \mathrm{mtr}$ \\
\hline & $\Sigma$ & $\begin{array}{l}43.9 \\
\text { mtr }\end{array}$ & $46 \mathrm{mtr}$ \\
\hline
\end{tabular}

Selanjutnya data-data tersebut di atas dianalis dengan statistik deskriptif, dan hasilnya dapat dilihat pada tabel berikut ini;

Tabel 4. Statistik Deskriptif Data Penelitian

\begin{tabular}{|l|r|r|r|r|r|r|r|}
\hline & $\mathrm{N}$ & $\begin{array}{r}\text { Mini } \\
\text { mum }\end{array}$ & $\begin{array}{r}\text { Maximu } \\
m\end{array}$ & Sum & Mean & & $\begin{array}{r}\text { Std. } \\
\text { Deviatio } \\
n\end{array}$ \\
\hline & $\begin{array}{r}\text { Statist } \\
i c\end{array}$ & $\begin{array}{r}\text { Stati } \\
\text { stic }\end{array}$ & Statistic & $\begin{array}{r}\text { Statis } \\
\text { tic }\end{array}$ & $\begin{array}{r}\text { Statisti } \\
c\end{array}$ & $\begin{array}{r}\text { Std. } \\
\text { Erro } \\
r\end{array}$ & Statistic \\
\hline $\begin{array}{l}\text { DOL AWAL } \\
\text { SISTIM SET }\end{array}$ & 10 & 3.2 & 5.5 & 43.9 & 4.390 & .200 & .631 \\
\hline $\begin{array}{l}\text { DOL AKHIR } \\
\text { SISTIM SET }\end{array}$ & 10 & 3.2 & 6.0 & 46.0 & 4.600 & .239 & .757 \\
\hline $\begin{array}{l}\text { Valid N } \\
\text { (listwise) }\end{array}$ & 10 & & & & & & \\
\hline
\end{tabular}

Berdasarkan pada tabel di atas dapat dilihat bahwa; hasil tes awal memiliki nilai tertinggi 5.5 meter, nilai terendah 3.2 meter, dan nilai rata-ratanya adalah 4.39 meter. Selanjutnya setelah diberikan perlakuan diperoleh nilai tertinggi 6.0 meter, nilai terendah 3.2 meter, dan nila rata-ratanya adalah 4.60 meter. Dengan demikian dapat disimpulkan bahwa terdapat peningkatan daya ledak otot lengan pada kedua kelompok setelah diberikan perlakuan.

\section{A. Pengujian Hipotesis}

Sebelum melakukan pengujian Hipotesis tentang sistem set terhadap peningkatan kemampuan daya ledak otot lengan pada atlet bolabasket fik unp (Y) terlebih dahulu dilakukan uji persyaratan analisis yaitu uji normalitas sebaran data. Setelah data diuji dengan persyaratan analisis dilakukan uji Hipotesis.

\section{Uji Normalitas}

Uji normalitas data menggunakan Kolmogorov-Smirnov $\mathrm{Z}$ test, dan hasil yang diperoleh menunjukan bahwa data kedua kelompok berdistribusi normal yaitu $p>\alpha$ 0.05 . Untuk lebih jelasnya dapat dilihat pada tabel di bawah ini;

Tabel 5. Uji Normalitas Data

\begin{tabular}{|r|r|r|}
\hline & & $\begin{array}{r}\text { DOL AWAL } \\
\text { SISTIM SET }\end{array}$ \\
\hline $\mathrm{N}$ & & 10 \\
\hline Normal Parameters & Mean & 4.390 \\
\hline & Std. Deviation & .631 \\
\hline Most Extreme & Absolute & .168 \\
Differences & & \\
\hline & Positive & .131 \\
\hline \multicolumn{2}{|c|}{ Kolmogorov-Smirnov } \\
$Z$
\end{tabular}

\section{Uji Homogenitas}

Hasil uji homogenitas data dengan melalui uji varians, memperlihatkan bahwa data memiliki keragaman yang tidak berbeda dengan $p>\alpha$ 0.05. Dengan demikian dapat disimpulkan bahwa data awal berada dalam keadaan homogen. 
Tabel 6. Uji Hemogenitas Varians Data Penelitian

Test of Homogeneity of Variances

\begin{tabular}{|r|r|r|r|}
\hline $\begin{array}{r}\text { Levene } \\
\text { Statistic }\end{array}$ & df1 & df2 & Sig. \\
\hline .118 & 1 & 18 & .735 \\
\hline
\end{tabular}

\section{Uji Hipotesis}

Terdapat pengaruh yang signifikan latihan sistim set terhadap peningkatan daya ledak otot lengan )

Hasil analisis data dengan menggunakan uji t, menunjukan bahwa latihan sistem set tidak dapat meningkatkan daya ledak otot lengan dengan bermakna, yaitu $\mathrm{t}_{\text {hit }} 1.74<\mathrm{t}_{\text {tab }}$ 2.26 dan $p 0.11>\alpha 0.05$, artinya tidak terdapat perbedaan antara hasil tes awal (pretest) dengan tes akhir (post-test) setelah diberikan perlakuan latihan sistim set. Dengan demikian dapat disimpulkan bahwa Ha yang diajukan ditolak.

Tabel 7. Uji t DOL Awal dan Akhir Sistem Set

Paired Samples t-test
\begin{tabular}{|l|r|r|r|r|r|}
\hline & & $\mathrm{N}$ & Correlation & Sig. & $\mathrm{t}$ \\
\hline Pair 1 & $\begin{array}{r}\text { DOL AWAL } \\
\text { dan AKHR } \\
\text { SISTIM SET }\end{array}$ & 10 & .864 & .116 & 1.741 \\
\hline
\end{tabular}

\section{Pembahasan}

Sistem set merupakan salah satu metoda latihan melalui beberapa latihan yang tujuannya melihat kemampuan daya ledak otot lengan, untuk tercapainya tujuan tersebut latihan yang diberikan dipengaruhi oleh, intensitas, volume, repetisi dan recovery. dimana atlet diharuskan menyelesaikan suatu bentuk latihan di pos yang sama sampai 3 set tanpa pindah-pindah, setelah tiga set kemudian pindah ke pos berikutnya.

Daya ledak merupakan salah satu dari komponen biomotorik yang penting dalam kegiatan olahraga, karena daya ledak akan menentukan seberapa jauh melempar bola, sehingga otot harus mengerahkan tenaga dengan kuat dalam waktu yang singkat untuk memberikan momentum yang paling baik pada tubuh atau objek untuk membawa ke objek yang diinginkan.

Setelah dilakukan analisis data terhadap hasil penelitian dengan menggunakan analisis uji t terhadap hipotesis yang diajukan teruji secara empiris. Temuan penelitian seperti yang dikemukakan di atas merupakan hasil analisis secara statistic dan perlu dikaji sebagai berikut:

Sistim set tidak terdapat pengaruh yang signifikan terhadap peningkatan daya ledak otot lengan.

Sesuai dengan analisis data dapat dilihat $\mathrm{t}_{\text {hit }} 1,74<\mathrm{t}_{\text {tab }} 2,26$ dan p 0,11 $>\alpha 0,005$. hal ini berarti latihan sistem set kurang dapat meningkatkan daya ledak otot lengan. Peneliti melihat kurangnya keseriusan atlet saat melakukan gerakan, sehingga tidak terlihat peningkatan secara berarti.

Faktor lain yang dapat disimpulkan bahwa latihan sistem set latihan yang tidak sistematis, menurut (Harsono 1993:2)"Sistematis berarti bahwa latihan dilaksanakan secara teratur, terencana, menurut jadwal, menurut pola dan berkesinambungan, jadi latihan yang tidak memenuhi salah satu atau lebih persyaratan tersebut maka latihannya tidak sistematis.

Tidak terdapatnya pengaruh yang sigifikan dari sitem set ini terhadap peningkatan daya ledak otot lengan disebabkan salah satunya tidak terkontrolnya aktifitas sampel baik sebelum latihan ataupun sesudah latihan diberikan, juga kurang memperhatikan asupan gizi yang dikonsumsi oleh sampel sehingga dapat mempengaruhi kondisi fisik mereka baik pada saat latihan berlangsung ataupun saat pengambilan tes akhir.

Agar latihan dapat dikatakan bagus seorang pelatih seharusnya memperhatikan lebih teliti saat melaksanakan perlakukan. Seperti yang dikatakan (Harsono 1993:11) yaitu

1. Latihan yang diberikan oleh pelatih adalah benar-benar bermanfaat dan sesuai dengan kebutuhan atlet.

2. Koreksi yang tepat dan kontruktif selalu diberikan manakala atlet melakukan kesalahan.

3. Pengawasan terhadap setiap detail gerakan dilakukan secara teliti.

4. Setiap kesalahan gerak segera diperbaiki.

\section{Kesimpulan}


Berdasarkan analisis data dan pembahasan di atas, maka penelitian dapat disimpulkan bahwa: Sistem set tidak terdapat pengaruh yang signifikan terhadap peningkatan daya ledak otot lengan dengan nilai $\mathrm{t}_{\text {hit }} 1.74<\mathrm{t}_{\mathrm{tab}} 2.26$ dan $\mathrm{p} 0.11$ $>0.05 \alpha$.

\section{DAFTAR PUSTAKA}

Afdal, M. (1991). Pengaruh latihan Kekuatan Sistem Set dan Sistem Sircuit Weight Training terhadap Kekuatan Otot pada Mahasiswa FPOK IKIP Padang, Tesis, IKIP Padang.

Ambler, VIC. (1982). Basketball (The basics For Coach and Player). London: Satelit Offset.

Arsil. (1999). Pembinaan Kondisi Fisik. Padang: FIK UNP.

Basoeki, Soejono. (1998). Anatomi dan Fisiologi Manusia. Jakarta : Depdikbud.

Bompa, Tudor O. (1994). Power Training for Sport. Canada : Mocaic Press.

Delavier, Frederic (2001). Strength Training Anatomy. Canada : Publishing of Human Kinetic.

Harsono. (1988). Coaching dan Aspek-aspek Psikologis dalam Coaching. Jakarta: P2LPTK.

Harsono (1993) Prinsip-prinsip Pelatihan. Jakarta: P2LPTK.

Isparjadi (1988). Statistik Pendidikan. Jakarta : Depdikbud, Dikti : P2 LPTK.

Kusyanto, Yanto. (1999). Penuntun Belajar Pendidikan Jasmani dan Kesehatan 1 (Berdasarkan Kurikulum Baru GBPP 194).

\section{Bandung : Ganeca Exact Bandung.}

Nawawi, Umar. (2008). Fisiologi Olahraga. Padang : FIK UNP.

PB. PERBASI (2005). Bahan Penataran dan Penyegaran Bagi Pelatih Tingkat Dasar. Padang : Pengda Perbasi Sumbar.

PB. PERBASI .(2008). Pengaturan Permainan Bola Basket. Jakarta : PERBASI.

Sodikoen, Imam. (1992). Olahraga Pilihan Bolabasket. Padang : FPOK IKIP Padang.

Syafruddin. (1993). Pengantar Ilmu Melatih. Padang : FPOK IKIP Padang.

Syahara, Sayuti. (2004). Kemampuan Biomotorik dan Metodologi Pengembangan (terjemahan). Padang: FIK UNP Padang.

Syahara, Sayuti. (2005). Fisiologi Olahraga. Padang: Konsentrasi Manajemen Pendidikan Olahraga Pascasarjana UNP.

Tomoliyus. (2001). Pendekatan Keterampilan Taktis dalam Pembelajaran Bola Basket. (konsep dan metode). Jakarta : Depdiknas Dirjen Pendidikan Dasar dan Menengah dan Dirjen Olahraga.

Wawan Eko Yulianto. (2007). Dasar-dasar Bola Basket (terjemahan). Bandung : Pakar Raya.

Witarsyah. (2005). Bola Basket Pendalaman. Padang : FIK UNP.

Yendrizal. (1997). Pengaruh Latihan Beban dan Kemampuan Motorik Otot terhadap Kekuatan Otot. Tesis. Jakarta. 
